\title{
My Last Issue-a Farewell to Cardiovascular Drugs and Therapy
}

\author{
Willem J. Remme ${ }^{1}$
}

Published online: 18 December 2019

(C) Springer Science+Business Media, LLC, part of Springer Nature 2019

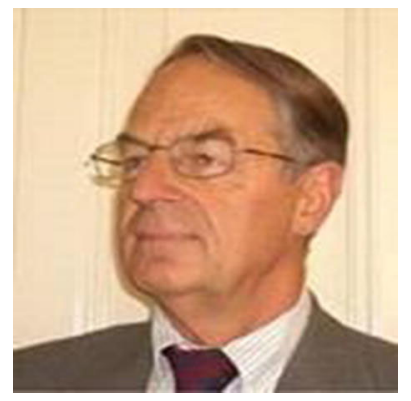

Willem J. Remme Editor-in-Chief 2001-2019

When I accepted the position of Editor-in-Chief of Cardiovascular Drugs and Therapy (CDT) in January 2001, I never thought that this would last for 19 years, possibly 2 periods of 5 years, not more. And that then a new person would take over, as was the routine with most journals at that time.

However, it turned out to be a different story. While I grew in my new job, I started to like it more and more, the journal did well with a gradually increasing impact factor. Moreover, I had straight from the beginning excellent support from the Associate Editors and Editorial Board members. Most importantly, the Publisher appeared to be happy. And, thus, after the two 5-year periods, a third was agreed upon, followed by 4 more years for various reasons, including finding a successor for the job.

I have always liked being an Editor for CDT. It has a very wide scope, covering drug, device and cell therapy in all areas of cardiovascular medicine including basic research, clinical drug and device studies, clinical trials, and pharmaco-epidemiology and pharmaco-economics.

Handling such a journal is quite interesting and if it goes well very rewarding, but also extremely difficult, probably much more so than handling a journal selectively focusing on a specific disease area. The Editor-in-Chief on his own is not able to

\section{Willem J. Remme}

\footnotetext{
Sticares Cardiovascular Research Foundation, Rhoon, the Netherlands
}

oversee the full scope our journal aims to cover, at least I cannot. It is only do-able having full support of the Editorial Board, which luckily I have had from the beginning, although even with this help the Editor still needs to spend a lot of time searching the literature for appropriate reviewers, who then also must be willing to accept, which unfortunately is often not the case.

Against this background, I think it is fair to state that over the years, we have done well. Some facts to support this:

Our Impact Factor grew from 1,009 in 2001 to 4.181 in 2018. Based on this, CDT is currently the second best journal in its field.

Downloads increased significantly by $74 \%$, and citations have more than doubled. In this regard, it should be noted that selfcitations are not pursued and are rare, only $2 \%$.

CDT has recently also become known in social media with 81 article mentions on the Social Web citations in 2016, 191 in 2017 and 237 in 2018 .

Submissions have more than tripled since 2001 and increased by $26 \%$ since 2016. Almost half of all submissions came from Asia-Pacific between January 2016 and June 2019, and 34\% from China alone. In contrast, submissions from China make up only $11 \%$ of all papers accepted, and $14 \%$ from the rest of Asia-Pacific. Most papers accepted are from the USA and Europe, which each make up about $1 / 3$ of submissions. The rejection rate is between 74 and $78 \%$, the last years, and increased to $80 \%$ in 2019.

Average days to first decision is 26 days in 2019 , and the turnaround time from submission to final decision on a manuscript 
has been anywhere between 2 and 4 months over the last few years. This includes time spent with reviewers and author revisions.

\section{Journal Highlights}

During these 19 years, there have been quite a few bestsellers. Articles which reached a record of high citations and/or downloads. On top of the list, by far, stands the PRIMO study by Eric Bruckert, published in 2005. Professor Bruckert, Board member since 2001, got a record 656 citations and 5200 downloads with his publication of the occurrence and predictors of mild to moderate muscular symptoms with high-dose statin therapy in 7924 hyperlipidemic patients in France [1].

Other highly cited articles were: EPHESUS trial design (Bertram Pitt, 235 cites [2]), Necrostatin, a potentially cardioprotective agent (Derek Yellon, 200 cites [3]), Phospholipase A2 biochemistry (John Burke, 196 cites [4]), and Oxidized LDL, LOX-1 and atherosclerosis (Sona Mitra and Jawahar Mehta, 169 cites [5]).

Highlights also included the publication of special issues and sections organized and edited by Editorial Board members. In line with the scope of the journal and the composition of the Board the topics varied considerably, ranging from basic research, e.g., LOX-1: A Novel Target for Treatment of Cardiovascular Diseases by Jawahar Mehta[6], to clinical themes such as Update on Pharmacological Agents for Management of Chronic Stable Angina by Jason Tarkin and Juan Carlos Kaski [7]. However, where possible editors would strive to reach a balance between "bench" and "bedside", i.e., Masafumi Kitakaze (Translation of Cardioprotection From Bench to Bedside [8])

As there have been many special publications, limited space does not allow me to mention all of them. Those I want to pay attention to in addition to the special sections mentioned above include the following:

- Building a Bridge to the Future of Cardiovascular Drugs and Therapy by Sean Davidson [9].

- Women and Heart Disease; a Focus Issue by Jawahar Mehta [10].

- Perivascular Adipose Tissue Biology and Cardiovascular Disease by Eugene Chen [11].

- Late Sodium Current in the Heart: Basic and Clinical Aspects by Carol Ann Remme [12].

- Biological Causality: When Experimental Models and Human Genetics Conflict by Robert Rosenson and Wolfgang Koenig [13].

- Phospholipase, Inflammation and Cardiovascular Disease also by Robert Rosenson [14].

These special issues were excellent and contributed greatly to the success of the journal.
Of importance, the editors of these special sections and issues are also Associate Editors and deeply involved in handling the journal, as all other Associate Editors are. I owe them all a lot. Without their help in valuating manuscripts worthy of peer review and finding appropriate reviewers my job would have been very difficult indeed. Moreover, Associate Editors are essential when it comes to finding new Board members and suggesting topics for special sections. I thank all of them for the support they have given me.

I am equally grateful for the support of the other members of the Editorial Board. Although they are less frequently approached, these members are often asked to review, which all accept, often several times per year, and in addition, themselves submit articles to the journal. I wish to thank all those Board members who have supported the journal and me during my time as Editor-in-Chief. I hope that they will appreciate that CDT has been successful as a result of their contribution.

One person needs to be mentioned specifically, Bob Rosenson, who has been my co-Editor-in Chief for 2 years (2017 and 2018). During that time, he invited quite a few new Board members and put them to work. In addition, he was the driving force behind the submission of several good manuscripts, in addition to his own regular articles. Bob and I have known each other for a long time, and I have a great respect for him. We worked very well together as co-Editors, and I am quite sorry that he, for personal reasons, decided not to continue.

Finally, I am grateful for the Publisher's support. Throughout the years, Lisa Aquilino has been very helpful and is actively involved in a very constructive way in our efforts to further improve the journal. She is also a very kind and amiable person. It has been a real pleasure to work with her.

After 19 years, I will step down, and I do not like it at all. However, I am also convinced that it is both necessary and good for CDT that a new person will take over with new ideas and a view on how to manage the journal differently and bring it to a higher level.

In this regard, I am convinced that my successor Yochai Birnbaum can fit the bill.

He has experience as Associate Editor, has published quite a few articles for the journal (some highly cited), and, most importantly, is enthusiastic to perform his new role. Moreover, he is a hard worker. I have experienced this already during the last weeks of our transition.

I wish him a successful editorship and a bright future for Cardiovascular Drugs and Therapy.

\section{References}

1. Bruckert E, Hayem G, Dejager S, Yau C, Bégaud B. Mild to Moderate Muscular Symptoms with High Dosage Statin Therapy in Hyperlipidemic Patients-the PRIMO Study. Cardiovasc Drugs Ther. 2005;19:402-14. 
2. Pitt B, Williams G, Remme W, et al. The EPHESUS trial: eplerenone in patients with heart failure due to systolic dysfunction complicating acute myocardial infarction (EPlerenone's neuroHormonal Efficacy and SUrvival Study). Cardiovasc Drugs Ther. 2001;15:79-87.

3. Smith C, Davidson S, Lim S, Simpkin J, Hothersall J, Yellon D. Necrostatin: a Potentially Novel Cardioprotective Agent? Cardiovasc Drugs Ther. 2007;21:227-33.

4. Burke J, Dennis E. Phospholipase A2 Biochemistry. Cardiovasc Drugs Ther. 2009;23:49-59.

5. Mitra S, Goyal T, Mehta J. Oxidized LDL, LOX-1 and Atherosclerosis. Cardiovasc Drugs Ther. 2011;25:419-29.

6. Mehta J, Khaidakov M, Hermonat P, Mitra S, Wang X, Novelli G. LOX-1: a New Target for Therapy for Cardiovascular Diseases. Cardiovasc Drugs Ther. 2011;25:495-500.

7. Tarkin J, Kaski JC. Update on Pharmacological Agents for Management of Chronic Stable Angina : Introduction. Cardiovasc Drugs Ther. 2016;30:339-40.

8. Kitakaze M. How to Mediate Cardioprotection in Ischemic Hearts-Accumulated Evidence of Basic Research Should Translate to Clinical Medicine. Cardiovasc Drugs Ther. 2010;24:217-23.

9. Davidson SM. Editorial to: Building a Bridge to the Future of Cardiovascular Drugs and Therapy. Cardiovasc Drugs Ther. 2017;31:51-2.
10. Mehta JL. Women and Heart Disease; a Focus Issue. Cardiovasc Drugs Ther. 2015;29:317-8.

11. Chen YE. Editorial: the Yin and Yang of Perivascular Adipose Tissue in Vascular Disease. Cardiovasc Drugs Ther. 2018;32:477-9.

12. Remme CA, Wilde A. Late Sodium Current Inhibition in Acquired and Inherited Ventricular (Dys)function and Arrhythmias. Cardiovasc Drugs Ther. 2013;27:91-103.

13. Rosenson R, Koenig W. Special Issue on Biological Causality: When Experimental Models and Human Genetics Conflict. Mendelian Randomization Analysis for Selection of Therapeutic Targets for Cardiovascular Disease Prevention: a Note of Circumspection. Cardiovasc Drugs Ther. 2016;30(1):65-74.

14. Rosenson R. Special Section: Phospholipase, Inflammation and Cardiovascular Disease. Future Role for Selective Phospholipase A2 Inhibitors in the Prevention of Atherosclerotic Cardiovascular Disease. Cardiovasc Drugs Ther. 2009;23:93-101.

Publisher's Note Springer Nature remains neutral with regard to jurisdictional claims in published maps and institutional affiliations. 